\title{
The Role of Family Factors on the Relapse Behavior of Male Adolescent Opiate Abusers in Kerman (A Province in Iran)
}

\author{
Samira Golestan \\ Faculty of Human Ecology, University Putra Malaysia \\ No.19-13, Pangsapury Vista Impiana, Taman Bukit Serdang Seksyen 10, 43300, Seri \\ Kembangan, Selangor, Malaysia \\ Tel: 60-17-201-1519 E-mail: Samira_Golestan@yahoo.com \\ Dr. Haslinda Binti Abdullah \\ University Putra Malaysia \\ UPM Serdang, Selangor, 43400, Malaysia \\ Tel: 60-19-376-2293 E-mail: lynn@putra.upm.edu.my \\ Dr. Nobaya Binti Ahmad \\ University Putra Malaysia \\ UPM Serdang, Selangor, 43400, Malaysia \\ Tel: 60-19-361-0062Ｅ-mail: nobaya@putra.upm.edu.my
}

\author{
Ali Anjomshoa \\ Azad University: Kerman Branch
}

No.19-13, Pangsapury Vista Impiana, Taman Bukit Serdang Seksyen 10, 43300, Seri

Kembangan, Selangor, Malaysia

Tel: 60-17-354-0418Ｅ-mail: Ali.Anjomshoa@yahoo.com

\begin{abstract}
This study explores the significance of the family factors on drug use and its effects on relapse. In this respect, the effects of parental substance use, family conflict, and family structure are discussed in this research. The family, as a fundamental social unit of society, can be expected to exert remarkable influences on the development of social behaviors such as adolescent substance use and also relapse (Rouholamini, 2002). Since nearly $90 \%$ of drug abusers in Iran live with a family member (Mokri, 2002), therefore family has an important role to reduce the high rates of relapse after detoxification. Therefore, this study considers three factors: Parental substance use, Family Conflict, and Family Structure. The objective of this study is to examine the effects of family factors (Parental substance use, Family Conflict, and Family Structure) on relapse behavior among male adolescent opiate users in Kerman.

In this research 226 adolescents between the ages of 13 to 20 were selected based on ten rehabilitation centers to answer the Self-administered questionnaire. Results showed that there were important relationships between these factors with relapse in adolescents. The study proposes some suggestions in order to prevent relapse after treatment in adolescents.
\end{abstract}

Keywords: Family, Parental substance use, Conflict in family, Family structure, Adolescent, Opiate addiction 


\section{Introduction}

Nowadays, addiction is the most evil phenomenon of the present century, which threatens life, economy, families, and societies (Youth at the United Nations, 2006). Actually, addiction to drugs is a big social and personal problem, which influences not only the mind and body of the addict but also the health of society concerning social, economical, political, and cultural issues (Farjad, 2000). Nowadays, adolescent drug use is a problem all over the world (Mental Health Touches, 2006). Unfortunately, addiction percentage in lower ages is increasing (Farjad, 2000). United Nation announces that about 25 percent of addicts in Asia and Eastern Europe are under the age of 20 (Youth at the United Nations, 2006). During recent decades, adolescent substance use is widespread in Iranian communities, schools, and families, causing prevalent social, psychological, familial, and economic disasters (Azizi, 2004; Mokri, 2002). According to Azizi (2004), drug use among Iranian adolescents is increasing. Furthermore, the rise of using drug has led to the quick emergence of infectious diseases such as (HIV) and Hepatitis (Mokri, 2002).

Considering the increase in adolescent drug abuse, the demand for treatment of drug addicted adolescents is increasing. Although detoxification programs have been implemented in recent years, unfortunately, relapse rates are as high as 95\% (Razzaghi, Rahimi, Hosseini, Madani, \& Chatterjee, 1999). The reason that affects on drug abuse can also affect on relapse in adolescents (Annis \& Davis, 1997). According to Gorski (2001), 78\% of adolescents relapsed after they stopped using drugs for six months.

As Naderi (2000) states, in Iran, the family environment of drug addicted adolescents has also been considered as being primitive, less cohesive, angrier, and more conflicted than those without drug addiction in family members. Meanwhile those parents who use drugs make their adolescents imitate such offence while considering it as something acceptable (Mokri, 2002). According to Amini (2000), in Iran the major factor causing addiction and also returning to drug in the adolescents is originated from family problems (parental substance use, family conflict, and family structure), because nearly $90 \%$ of the adolescents live with their family members (Mokri, 2002).

Although a lot of attempt that Iranian national drug control headquarters had done in direction of prevention, unfortunately the percentage of those who involved in drugs still increase, and also relapse rates are as high as $95 \%$, especially among male adolescents in Kerman (Razzaghi, et al., 1999; Saeed, 2000). Usually the recovery processes are not done completely and just attend to the physical dimension by detoxification without any consideration for the important factors such as family factors (Parental substance use, Family Conflict, and Family Structure), because the addict after detoxification return to family, almost $90 \%$ of drug abusers in Kerman live with a family member, cannot expect a perfect quit for addict person without thinking about these factors carefully (Ghorbanhosseini, 1990). So this study attends to examine three sub factors in family, namely parental substance use, family conflict, and family structure in Kerman.

\section{Methodology}

To achieve the purpose, data were collected from 226 opiate addicted male adolescents, aged 13-20, who had referred to rehabilitation centers, and had at least once relapse in Kerman. The method of data collection was self-administered questionnaire in a quantitative study. Demographic information such as age, education, level, and occupation status were assessed by using a questionnaire of demographic data. The next part includes questions about family factors that are related to relapse. Questions pertaining to the family factors on relapse behavior were measured using the Likert scale in the form of "(1) Negligible, (2) Low, (3) Moderate, (4) High, and (5) Very high" with each item in the questionnaire. The reliability coefficients for family factors are .74. It took about 20 minutes to complete the questionnaire. The result was a quantitative analysis study. Two statistical procedures, descriptive statistics and inferential statistics, were used for data analyses in this study. In order to ensure that the data were normally distributed the normality test was calculated for all measures in regard to this study. To examine the research hypothesis, the Pearson correlation test is applied along with scatter plot to appoint the connection between the two variables.

\section{Results of the study}

Participants were all male with an average age of 17.5; the highest level of education belonged to the associate degree that included (36.3\%); most of them (61.1\%) were unemployed, and most of their families (58.8\%) live together. Their income or spending money that was $(72.7 \%)$ belonged to the lowest price (0-70000 Tomans). Mostly, their reason for quitting was related to feeling tired that comprised (35\%). Pearson correlations among family factors and relapse showed that relapse was correlated with family factors (parental substance use, family conflict and family structure). Considering data analysis, it is specified that Pearson correlations between family factors and relapse addiction of respondents are 0.315 in rank order and with p-value is 0.00 in rank order which is less than $\alpha=0.01$ significance value, thereby there is significant relationship between these two variables with regard to correlation coefficient that is shown in table (1).

The results of the study have shown that unfortunately adolescents that give up their addiction in Kerman suffer from family problems like parental substance use, family conflict and family structure (divorce in family or death of one 
parent) when they completed their first treatments and the family problems as factors precipitating relapses after treatment amongst opiate adolescents in Kerman. Considering the way of spot scattering in scatter plots show a direct relation between relapse and the family variables (parental substance use, family conflict and family structure). It means that whenever a person has a bad family environment (high parental substance use, high level of family conflict and family structure) he or she would be placed in relapse situation again.

\section{Discussion}

The objective of this study was to explore the family factors on relapse behavior among adolescent opiate users in Kerman (a big province in Iran). Factors that are shown in this research were family factors like parental substance use, family conflict and family structure. In Kerman, family plays a very important role in controlling adolescent, and any damages to family makes adolescent take refuge in drugs (Mokri, 2002). The family as the fundamental social unit of society can be expected to exert influential influences on the development of social behaviors such as adolescent substance use and also relapse (Rouholamini, 2002). Meanwhile those parents who use drugs make their adolescents imitate such offence while considering it as something acceptable (Mokri, 2002). Literatures have successfully recognized family risk factors for adolescent in drug abuse that include rejection by parents, parental and sibling substance use, divorce in family, and conflict in family (Cattarello, Clayton, \& Leukefeld, 1995; Madu \& Matla, 2003). Drug abusers tend to report a meaningfully poorer relationship with their parents compared to non-drug abuser (Rouholamini, 2002). Also, Denton and Kampfe (1994) show that parental absence due to death, break-ups, or divorce increases the probability that adolescent will abuse drugs. Furthermore, as Dodgen and Shea (2000), Fraser (2002) and Van Der Westhuizen (2007) indicated Parental substance use, lack of parental support, lack of communication with parents, divorce in family, problems in the parent relationship has affect on the participates following treatment, and causes return to drug. Based on social learning theory people acquire their behavior by observing what others do, imitating behaviors that are reinforced and evading behaviors that are punished (Bandura, 1977). According to cognitive-social learning model that is developed over the past 30 years by Marlatt and his colleagues (Marlatt \& Gordon, 1985; Parks, Anderson, \& Marlatt, 2001), drug abuse behavior like other types of behavior, is learned through a process of modeling and reinforcement and as Bandura (1977) indicated that relapse is learning behavior, also Marlatt \& Gordon (1985) stated that relapse is the result of a learning process and cognitive-behavioral. A cognitive-social learning model is one of the most powerful theoretical frameworks that have been used to the problem of relapse in the using drug area.

Parental substance use has been identified as one of the most common risk factors for substance use and also relapses in adolescents (Cattarello, et al., 1995; Van Der Westhuizen, 2007). Also other researcher shows that parental use is often a predictor of relapse in adolescent (Denton \& Kampfe, 1994; Thomas \& Hsiu, 1993; Van Der Westhuizen, 2007). The studied literature agrees that parents' drug use is a strong predictor of addiction among their adolescents (Fraser, 2002; Goodwin, 2000; Mc Whirter, Mc Whirter, Mc Whirter, \& Mc Whirter, 2004). In addition, Dodgen and Shea (2000) confirm and state that substance use by the parents further place adolescents at risk. Family structure refers to variables such as family composition and single parent due to death or divorce. Ziaaddini (2005) has been reported that one third of the addicts come from broken homes (single parent families). According to literature poor parent-adolescent communication, poor family management, lack of parental warmth, and also lack of parental involvement, absence of parents (due to divorce, or death) further place adolescents at risk and causes relapse (Dodgen \& Shea, 2000; Fraser, 2002; Gouws, Kruger, \& Burger, 2000). Furthermore, Van Der Westhuizen (2007) demonstrates that there is significant relationship between parental involvement and parental warmth, lack of parental support, lack of communication with parents and problems in the parental system as aspects that caused relapse in adolescents after treatment. Another family factor that is related to drug use in adolescents and also effects on relapse after treatment is conflict between members of family. Madu \& Matla (2003) identified that family conflict was significantly associated statistically with more drug use among adolescents in South Africa. High levels of family conflict or low family cohesion have also been reported to significantly effect on relapse in adolescents (Amini, 2000; Naderi, 2000; Rouholamini, 2002). As mentioned above conflict in family is related to adolescent substance use (Rouholamini, 2002), and also has effect on relapse in adolescents because after treatment adolescents return to family and when they return home following treatment, their immediate environment may not be supportive of their recovery, so the adolescents in treatment may use a method of coping with the stress of parental conflict and return to substance use and relapse (Turner, Irwin, Tschann, \& Millstein, 1993). Because they need to have parental warmth and place for relaxation (Mokri, 2002), their parents' home and their family is the only place for the majority of adolescents to stay or to return after recovery and need a happy home to help them to reduce drug use.

Iran is in the procedure of developing and growing drug abuse treatment options for opiate and other drug dependent patients. These days community development is becoming more and more popular, powerful, value, prevalent and more important as a planning style to solve the community problems. Warren (1978) defines the Community development, as a process of helping community people to solve their problems. The goal of community development is to help people improve their social situations (Christenson \& Robinson, 1980). Self-help approach is one of the essential approaches in 
community development. Self-help approach is based on that people can, will and should work together to solve community problems (Littrell \& Hobbs, 1989). Self-help approach is becoming more significant as a planning style to solve the community problems and self-help is a community building approach and also it is a style of planning, decision making, and problem solving (Christenson \& Robinson, 1980; Littrell \& Hobbs, 1989). Self-help a serious emphasize on education about the problem and its sources. Self-help can exist as an institute, place or an interest group (Littrell \& Hobbs, 1989). The person is vulnerable but can improve huge strength in self-help groups (Kindernothilfe, 2002). Berger \& Neuhaus (1977) proposed empowerment as a way of improving individual by means of mediating social institutions. Self-help has become an essential part of treatment for behavior problems, emotional problems, also for manage stressful situation. Several people discover that self-help group is very useful source for empowerment and recovery. The drug dependence treatment programs should support patients to contribute in self-help group during and after treatment and also encourage parents who have adolescents with behavior problems like relapse to attend a parenting group for guideline and help (Kindernothilfe, 2002). In addition, self-help groups play a necessary role for the family members to know the addiction, they should be empowered in recovery process and to become involved in treatment (Mental Health Touches, 2006). These groups are useful in supporting the family, and dealing with the feelings related to the addiction and the participation of families in after treatment efforts as necessary to relapse prevention (Goodwin, 2000).

Kerman (a province of Iran) is the biggest province in Iran and is also located near the border of Iran and Afghanistan. This city is situated in the path of world transit drug, so drug is easily availability (Mokri, 2002). Parental substance use, family conflict and also family structure such as divorce are prevalent is society of Kerman (Ziaaddini, 2005). In Kerman, Adolescent's first tries and exposure to drug are likely to be in the context of the family (Mokri, 2002). As above mentioned parents substance use is related to adolescent substance use, and also parents substance use effect on relapse in adolescents, because, adolescent after treatment return to family and nearly $90 \%$ of drug abusers in Kerman (a province in Iran) live with a family member (Mokri, 2002).So they need to have parental warmth and place for relaxation and also need to spend more time with parents (Mokri, 2002; Webb \& Baer, 1995).

Thus, family has a crucial role to reduce the high rates of relapse after detoxification. These are factors that are strongly related to relapse. The results of this study are consistent with results reported by (Friedman \& Utada, 1992; Havasi, 2001; Madu \& Matla, 2003; Mokri, 2002; Naderi, 2000).

\section{Conclusion and Recommendations}

As the results of this research identified family factors such as parental substance use, family conflict and family structure are significantly related to relapse in addicted adolescents. As researchers reveal several actions are needed to prevent relapse. Based on the results of this study, the following recommendations will be best to decrease relapse in Kerman.

As, Iran is in the procedure of developing and growing drug abuse treatment options for opiate and other drug dependent patients, the study findings regarding the family problems of opiate dependent patients and the relationship between family environment (high family conflict, parental substance use and structure family) and relapse behavior suggest that family interventions may be useful to improve treatment programs. Family interventions should be focused on family members; this can lead to lower conflict and more positive family atmosphere. Family empowerment has seen the largest use in chronic disorders in adolescents like relapse, in sum; family interventions have shown significant impact in improving health and quality of life in chronically disorders in adolescents (Dixon, 2001; Melnyk, 2004; Sherman, 2003).

The adolescents need self-help group in order to support them to avoid relapse. Self-help groups play an essential role for the family members to understand addiction, and they should be empowered in recovery process and become involved in the treatment (Mental Health Touches, 2006). Self-help groups are effective in supporting the family, and addressing the feelings related to the addiction and the involvement of families in aftercare efforts as necessary to prevent relapses (Goodwin, 2000). Parents should be able in their roles in order to support their adolescents in the treatment.

\section{References}

Amini, K. (2000). Exploring reasons of relapse among clients of public substance abuse treatment settings in Hamedan. University of Medical Sciences, Tehran.

Annis, H., \& Davis, C. S. (1997). Self-efficacy and the prevention of alcoholic relapse: initial finding from a treatment trial. New York: Preager.

Azizi, A. (2004). What is addiction? (4th ed.). Tehran Sabz.

Bandura, A. (1977). Social Learning Theory. New York: General Learning Press.

Berger, P. L., \& Neuhaus, R. J. (1977). To empower people, the role of mediating structures in public policy. Washington.DC: American enterprise institute for public policy research.

Cattarello, A. M., Clayton, R. R., \& Leukefeld, C. G. (1995). Adolescent alcohol and drug abuse (Vol. 14). Washington: 
American Psychiatric Press.

Christenson, J. A., \& Robinson, W. J. (1980). Community Development in America. Ames: Iowa State University Press. Denton, R. E., \& Kampfe, C. M. (1994). The relationship between family variables and adolescent substance abuse. Adolescence, 29 (114), 475-495.

Dixon, L. (2001). Pilot study of the effectiveness of the family-to-family education program. Psychiatric Services, 52(7), 965-967.

Dodgen, C. E., \& Shea, W. M. (2000). Substance use disorders. Assessment and treatment. SanDiego: Academic Press. Farjad, M. (2000). Addiction. Tehran: Badr.

Fraser, M. W. (2002). Risk and resilience in childhood. An ecological perspective. Washington: NASW.

Friedman, A. S., \& Utada, A. (1992). The family environment of adolescent drug abusers. Family Dynamics of Addiction Quarterly, 2, 32-45.

Ghorbanhosseini, A. (1990). The new way for Addiction and addict. Tehran: Amirkabir.

Goodwin, D. W. (2000). Alcoholism: the facts (3rd ed.). Oxford: Oxford University Press.

Gorski, T. T. (2001). Adolescent relapse prevention. [Online] Available: http://www.tgorskiarticles/adolescent (5/4/, 2006)

Gouws, E., Kruger, N., \& Burger, S. (2000). The adolescent (2th ed.). Sandown: Heineman publishers.

Havasi, N. (2001). Exploring and comparing parenting styles in familes with and without drug abuser adolescent. Alzahra University, Tehran.

Kindernothilfe. (2002). TheSelf-Help Approch: A peaple's movement for the well-being of their children. [Online] Available: www.self-help-approach.com/doc/SHG-Paper.pdf

Littrell, D. W., \& Hobbs, D. (1989). The self-help approach. In J. A. Christenson \& W. J. Robinson (Eds.). Ames (USA): Iowa state univeraity press.

Madu, S. N., \& Matla, M. P. (2003). Correlations for perceived family environmental factors with substance use among adolescents in South Africa. Psychological Reports, 92, 403-415.

Marlatt, G. A., \& Gordon, J. R. (1985). Relapse prevention: Maintenance strategies in the treatment of addictive behaviours. New York: Guilford.

Mc Whirter, J. J., Mc Whirter, B. T., Mc Whirter, E. H., \& Mc Whirter, R. J. (2004). At-risk youth. A comprehensive response. Canada: Brooks/Cole publishing Company.

Melnyk, B. M. (2004). Creating opportunities for parent empowerment program effects on the mental health/coping outcomes of critically ill young children and their mothers. Pediatrics, 113(6), 597-607.

Mental Health Touches (2006). Getting the facts about adolescent substance abuse and treatment. [Online] Available: http://www.athealth.com/Consumer/adolescentsufacts.html $(3 / 4,2006)$

Mokri, A. (2002). A brief overview of the status of drug abuse in Iran. Archives of Iranian Medicine, 5(3), 184-190.

Naderi, A. (2000). Exploring cultural, social, economical and familial factors of substance abuse in addiction camps in Bistoon. Azad Islamic University, Arak.

Nardi, D. A. (2000). Risk factors, attendence and abstinence patterns of low-income woman in perinatal addiction treatment lessons from a 5- year program. Issues mental health nursing, 18, 125 -138.

Parks, G. A., Anderson, B. K., \& Marlatt, G. A. (2001). Relapse Prevention Therapy in the Handbook of Alcohol Dependence and Problems. West Sussex, England,: John Wiley \& Sons, Ltd.

Razzaghi, E. M., Rahimi, A., Hosseini, M., Madani, S., \& Chatterjee, A. (1999). Rapid situation assessment (RSA) of drug abuse in Iran (IWO/UNDCP collaboration).

Rouholamini, S. (2002). Formative research on familial characteristics of drug users in Iran. Yale, New Haven.

Saeed, M. (2000). The effects of economics factors and social factors on addiction in rehabilitation centers in Kerman. Shiraz Shiraz.

Sherman, M. D. (2003). The Support and Family Education (SAFE) program: mental health facts for families. Psychiatric Services, 54(1), 35-37.

Thomas, B. S., \& Hsiu, L. T. (1993). The role of selected risk factors in predicting adolescent drug use and its adverse consequences. Addict, 28, 1549-1563.

Turner, R. A., Irwin, C. E., Tschann, J. M., \& Millstein, S. G. (1993). Autonomy, relatedness, and the initiation of health risk behaviours in early adolescence. Health Psychology, 12, 200-208.

Van Der Westhuizen, M. A. (2007). Exploring the experiences of chemically addicted adolescents regarding relapsing after treatment. University of South Africa.

Warren, R. (1978). The community in America (3th ed.). Chicago: Rand McNally.

Webb, \& Baer (1995). Influence of family disharmony and parental alcohol use on adolescent social skills, self-efficacy, and alcohol use. Addictive Behaviours, 127-135.

Youth at the United Nations. (2006). United Nations: World programme of action for youth. [Online] Available: http://www.un.org/esa/socdev/unyin/wpaydrug.html $(1 / 6,2006)$

Ziaaddini, H. (2005). The household survey of drug abuse in Kerman. Kerman Medical Sciences University, Kerman. 
Table 1. Results of Pearson Correlation Tests between family factors and relapse

\begin{tabular}{|cc|c|c|}
\hline & Family & Relapse \\
\hline Family & Pearson Correlation & 1 & $.315^{* *}$ \\
& Sig. (2-tailed) & & .000 \\
$\mathrm{~N}$ & 226 & 226 \\
\hline Relapse $\quad$ Pearson Correlation & $.315^{* *}$ & 1 \\
& Sig. (2-tailed) & .000 & \\
$\mathrm{~N}$ & 226 & 226 \\
\hline
\end{tabular}

**. Correlation is significant at the 0.01 level (2-tailed). 